\title{
Cold Plasma Pretreatment of Carbon Fibre Composite Substrates to Improve Adhesive Bonding Performance
}

\author{
Chiara Mandolfino, Enrico Lertora, and Carla Gambaro \\ Department of Mechanical Engineering, Polytechnic School, University of Genoa, Via all'Opera Pia 15, 16145 Genoa, Italy \\ Correspondence should be addressed to Chiara Mandolfino; chiara.mandolfino@unige.it
}

Received 30 June 2014; Revised 6 October 2014; Accepted 20 October 2014; Published 11 November 2014

Academic Editor: Stuart Edwardson

Copyright ( 2014 Chiara Mandolfino et al. This is an open access article distributed under the Creative Commons Attribution License, which permits unrestricted use, distribution, and reproduction in any medium, provided the original work is properly cited.

\begin{abstract}
The purpose of the paper is to investigate the effects of low pressure plasma treatment on wettability of carbon fibre reinforced polymer samples and on shear properties of adhesive bonded joints based on these substrates. In particular, two plasma process parameters, exposure time and power input, were optimized, performing contact angle evaluation on lap-shear tests. The plasma treatment was also compared with a conventional mechanical abrasion and untreated and only degreased specimens. The experimental results show that choosing the optimal parameters is possible to improve the wettability of composite substrates and reduce the contact angle.
\end{abstract}

\section{Introduction}

The use of composites is a growing reality in many industrial fields, from civil structures [1-3] to transport industry and especially in aeronautics components [4-9]. Some of their advantages are stiffness, ability to be tailored into complex shapes, strength, corrosion resistance, fatigue properties, and lightweight. In particular, the possibility to decrease the final weight of a manufactured structural component is essential in terms of fuel consumption reduction $[10,11]$.

Composites are primarily integrated in structures by means of mechanical fastening or adhesive bonding. Adhesives have many advantages in joining composite materials. Perhaps the most significant is that adhesive bonding does not require the composite to be drilled or machined. In fact, traditional techniques of mechanical fastening require the presence of metallic inserts for entering screws and rivets, which makes the manufacturing of the components more complex and does not allow modifications during construction. The use of bonding techniques also allows a better stress distribution as well as durable, lightweight, and aesthetic joints [12,13].

One of the most important processes to be set before realizing polymer based composite adhesive bonding is the pretreatment of the surface, due to the low surface energy showed by polymers. Recommended preparations of many composite adherends simply consist of a solvent wipe in order to remove dirt and oil followed by a mechanical abrading operation [12-15]. Another widely used technique to solve the problem of composite pretreatment is the peel ply [16]. Many studies have been performed on the preparation of composite substrates also using nonconventional techniques, such as laser $[17,18]$ or plasma treatments [19-23]. In particular, the aim of a plasma treatment, which can be considered as a physical-chemical procedure, is the functionalization of the specimen surfaces in order to increase surface energy and promote adhesion by providing specific interactions between the adhesive-adherend interfaces. The ionized gas generated by plasma discharge allows not only a deep cleaning of the samples exposed but also the activation and oxidation of polymeric surfaces without affecting bulk properties [12, 13, 24-29]. If we consider the different plasma treatments (corona, low-pressure glow discharge, atmospheric, etc.), the low-pressure glow discharge plasma, also called cold plasma, allows complete control of the processing parameters, and this leads to good homogeneity and reproducibility. Furthermore, it promotes a remarkable increase in adhesive properties of polymer films in terms of wettability of the surface $[30,31]$. It also offers a more long-lasting adhesion performance increase than any other treatment $[29,32]$. 
In the context of this study, cold plasma treatment was employed to modify polymer based composite surfaces. The wettability of the specimens was estimated for untreated, solvent degreased, abraded, and plasma treated specimens. The improvement in adhesion properties of these materials after plasma treatment was correlated with lap-shear strength of adhesive bonded joints.

\section{Materials and Methods}

2.1. Materials. The composite substrate used for this study was an epoxy resin reinforced with carbon fibres, supplied in sheets of thickness $1.5 \mathrm{~mm}$. The sheets were fabricated by laying up woven prepregs and cured in autoclave with a vacuum bag according to a confidential process. A plastic release film was used to remove the laminate from the mould. In this way, the surface of the composite was not contaminated by waxes or silicones, which could compromise the secondary bonding.

A two-part, low viscosity epoxy adhesive developed by $3 \mathrm{M}$ was used to manufacture the composite joints. It has a work life of approximately 70 minutes and a tack-free time of about 3 hours and is fully cured after 48 hours at room temperature [33].

2.2. Surface Pretreatment. In this paper two types of preliminary surface treatment were compared: standard abrasion and plasma pretreatment. Every treatment came after a preliminary cleaning process with acetone, in order to eliminate grease or pollutant particles from the surfaces.

Some untreated and only solvent degreased specimens were used as a basis for comparison. The mechanical abrasion was performed using a P240 grain carbide paper.

To evaluate the effect of cold plasma treatment, the samples were exposed to radio frequency (RF) low pressure plasma, using air as working gas. A glow discharge RF generator operating at $13.56 \mathrm{MHz}$ (model name: Tucano by Gambetti Kenologia, Italy) was used. The plasma is generated in a vacuum chamber between two electrodes: one that also acts as support for the samples to be treated and the other, positioned in the upper part of the chamber, allowing the samples to be completely crossed by the plasma beam. The chamber dimensions are: diameter $150 \mathrm{~mm}$, length $330 \mathrm{~mm}$; the total volume is about $5.5 \mathrm{~L}$. This kind of treatment allows treating of more components at once and this is an advantage when the treatment of a large number of small components is required.

In particular, the effect of plasma power input and exposure time as working parameters was investigated. The flow rate of $25 \mathrm{~cm}^{3} \mathrm{~min}^{-1}$ for the air input and a $0.5 \mathrm{mbar}$ working pressure were kept fixed. Table 1 summarizes all the surface treatments compared in this study and gives more details about the plasma pretreatments working parameters.

2.3. Evaluation of Contact Angle. Since polymeric based material wettability is very poor $[12,13,34,35]$, tests were carried out to verify the effects of cold plasma treatment

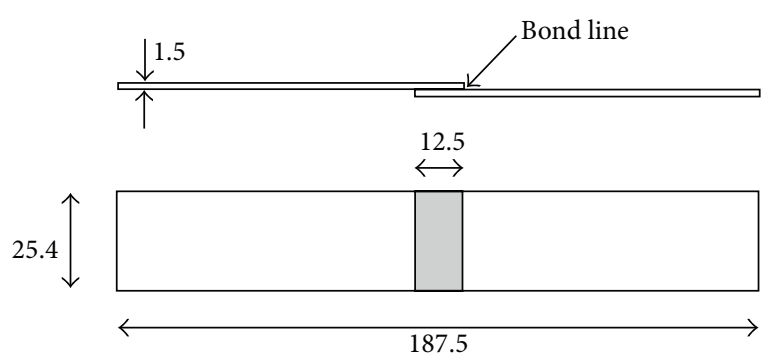

FIGURE 1: Dimension (in $\mathrm{mm}$ ) of the specimens realized according to ASTM D5868.

TABLE 1: Surface treatment summary and plasma working parameter details.

\begin{tabular}{|c|c|}
\hline Surface treatment & Description \\
\hline No treatment & Samples as-received \\
\hline Degreasing & Acetone wiping \\
\hline Abrasion & $\begin{array}{l}\text { Acetone wiping }+ \\
\text { P2 } 40 \text { grain carbide paper abrasion }\end{array}$ \\
\hline Plasma & $\begin{array}{l}\text { Acetone wiping + plasma discharge } \\
\text { (with different set-up parameters) }\end{array}$ \\
\hline \multirow[t]{2}{*}{ Set-up parameters } & Power input $(\mathrm{W}) \quad$ Exposure time $(\mathrm{s})$ \\
\hline & $5,30,60,180,300,450,600$ \\
\hline
\end{tabular}

on this parameter, compared to untreated and abraded specimens.

In particular the wettability of the substrate was evaluated by contact angle measurement. Demineralised water was dropped onto the surface of the sample using a calibrated pipette. All the measures were performed using a Leica Digital Microscope and X-Pro Software. At least three drops were measured and averaged on the samples treated.

2.4. Lap-Shear Test. Rectangular adherends, having dimensions $100 \times 25.4 \times 1.5 \mathrm{~mm}^{3}$, were prepared with different types of treatment and parameters and bonded for single tensile lap-shear tests. An overlapping of $12.5 \mathrm{~mm}$ was realized. The dimensions of the specimens refer to ASTM D 5868 [36] standard, as well as the lap-shear test conditions; five samples for each parameter setup were tested and averaged. Shape and dimension of the specimens are reported in Figure 1. All the specimens were realized with a specific equipment in order to maintain the same adhesive thickness of $0.5 \mathrm{~mm}$ and to have a high repeatability rate. Standard deviation was also calculated in percentage.

After the lap-shear test, the failure mode was analysed in order to evaluate the percentage of cohesive and adhesive failure. This investigation was carried out using a microscope and a specific function of its software.

\section{Results and Discussion}

3.1. Effects of Pretreatment on Contact Angle. As expected, the hydrophilic behaviour of the surfaces increased from the untreated to the abraded ones, reaching the minimum 
TABLE 2: Contact angle on CFRP surfaces.

\begin{tabular}{lccc}
\hline Surface treatment & $\begin{array}{c}\text { Mean contact } \\
\text { angle }\left(^{\circ}\right)\end{array}$ & $\begin{array}{c}\text { Standard } \\
\text { deviation }(\%)\end{array}$ \\
\hline No treatment & & 54 & 9 \\
Degreasing & & 52 & 6 \\
Abrasion & & & 10 \\
Plasma & Time (s) & & \\
\hline Power input (W) & 5 & 21 & 9 \\
100 & 60 & 20 & 5 \\
100 & 180 & 19 & 10 \\
100 & 300 & 16 & 15 \\
100 & 450 & 14 & 20 \\
100 & 600 & 12 & 18 \\
100 & 5 & 17 & 6 \\
200 & 60 & 14 & 20 \\
200 & 180 & 10 & 10 \\
200 & 300 & 7 & 25 \\
200 & 450 & 6 & 23 \\
200 & 600 & 5 & 30 \\
200 & & & \\
\hline
\end{tabular}

values of contact angle for the samples exposed to the plasma treatment.

Table 2 shows the values of contact angles for untreated, only degreased, abraded, and plasma treated CFRP substrates using a power input of $100 \mathrm{~W}$ and $200 \mathrm{~W}$ and different treatment times. The standard deviation in percentage is also reported as an indication of the repeatability of the results. Each value was measured as soon as the samples were withdrawn from the reactor.

The degreasing surface pretreatment does not affect the surface wettability of the composite substrate in any way. The contact angle remains almost unchanged for untreated, degreased, and abraded treated specimens, being close to $50^{\circ}$.

On the contrary, the application of a plasma discharge, even at low treatment times, produces a remarkable increase in surface wettability, reducing the contact angle by more than half compared with the untreated surface. Concerning the $100 \mathrm{~W}$ treatments, the best result in terms of surface wettability was obtained for treatments longer that $300 \mathrm{~s}$, even if at $180 \mathrm{~s}$ the result is considerable.

Figure 2 shows the variation of the demineralised water contact angle values of the low pressure plasma treated CFRP as a function of treatment time (from 5 to $600 \mathrm{~s}$ ). The graph also includes three horizontal lines representing the average value of contact angle of untreated, only degreased, and abraded substrates.

As it is easy to observe, the plasma treated sample surfaces experencied a significant decrease of the contact angle even using very short exposure times, while for longer times the advantage is not so substantial.

This is due to the fact that, during the first seconds of the plasma treatment, the free radicals produced by the action of

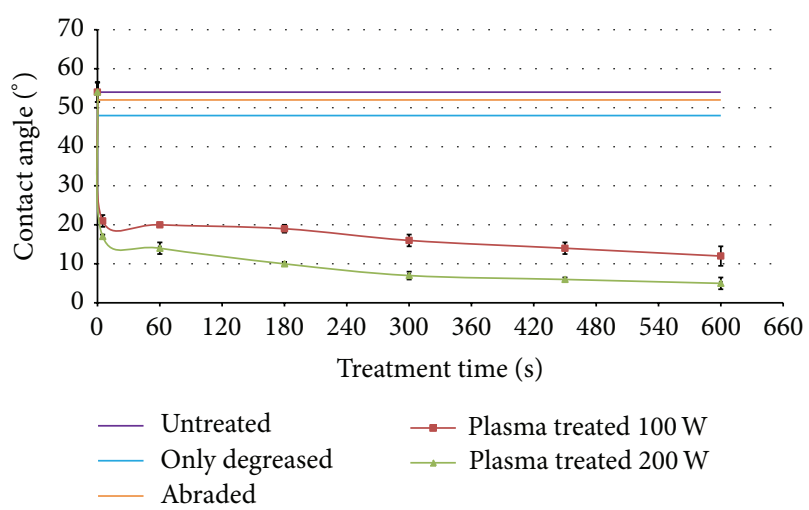

FIGURE 2: Variation of contact angle measured on sample surfaces in terms of treatment time and kind of treatment.

the plasma gas have high instability and reactivity and they could insert polar species and activate the surfaces [37].

The plasma power is linked with the potential to produce the functionalized layer on the surface. Because of the hydrophilicity of the functional group constituting the layer, the drops of water are easily absorbed into substrate surface and the contact angle decreases. This fact is being reported by [38]. In a previous work we have also reported an effective functionalization of polyethylene surfaces using the same plasma reactor [29].

These effects are generally supposed to be responsible for establishing strong interactions with adhesives, and their presence could be quantified by the surface energy polar component. Several authors calculate all the surface energy components in their works and express the link between plasma treatment and polar component $[10,21,26,28,30,37$, 38].

Indeed from the results, it is possible to observe that the surface wettability improved even using short plasma treatment time, and using a high power level it is possible to minimize contact angle values.

3.2. Effects of Plasma Pretreatments on Lap-Shear Strength. Adhesive joints between two CFRP substrates were realized, comparing only degreased, abraded, and plasma treated surfaces with untreated ones. Single lap-shear tests were conducted as mechanical characterization, using a $1.3 \mathrm{~mm} / \mathrm{min}$ test speed.

Figure 3 reports shear strength of the joints in terms of plasma treatment time, with two power input levels, $100 \mathrm{~W}$ and $200 \mathrm{~W}$, being fixed. Each point of the curve represents the average strength of five joints with the corresponding time-power setup and error bars. The graph also includes three horizontal lines representing the average value of shear strength of untreated, only degreased, and abraded substrates. Table 3 reports the numerical values of mean shear strength and standard deviation of these samples.

The mechanical properties of the adhesive joints are greatly influenced by the surface preparation. The results show that, without surface preparation, the joints presented very low shear strength, but it increased three times after only 
TABLE 3: Shear strength of adhesive joints with different surface treatments.

\begin{tabular}{lccc}
\hline Surface treatment & & $\begin{array}{c}\text { Mean shear } \\
\text { strength (MPa) }\end{array}$ & $\begin{array}{c}\text { Standard } \\
\text { deviation }(\%)\end{array}$ \\
\hline No treatment & & 1.24 & 83 \\
Degreasing & & 3.36 & 26 \\
Abrasion & 5.28 & 34 \\
Plasma & & & \\
\hline Power input (W) & Time (s) & 3.62 & 24 \\
\hline 100 & 5 & 4.36 & 7 \\
100 & 60 & 4.79 & 5 \\
100 & 180 & 4.34 & 7 \\
100 & 300 & - & - \\
100 & 450 & - & - \\
100 & 600 & 3.92 & 19 \\
200 & 5 & 5.67 & 12 \\
200 & 60 & 5.77 & 8 \\
200 & 180 & 7.30 & 6 \\
200 & 300 & 7.28 & 11 \\
200 & 450 & 5.79 & 8 \\
200 & 600 & & \\
\hline
\end{tabular}

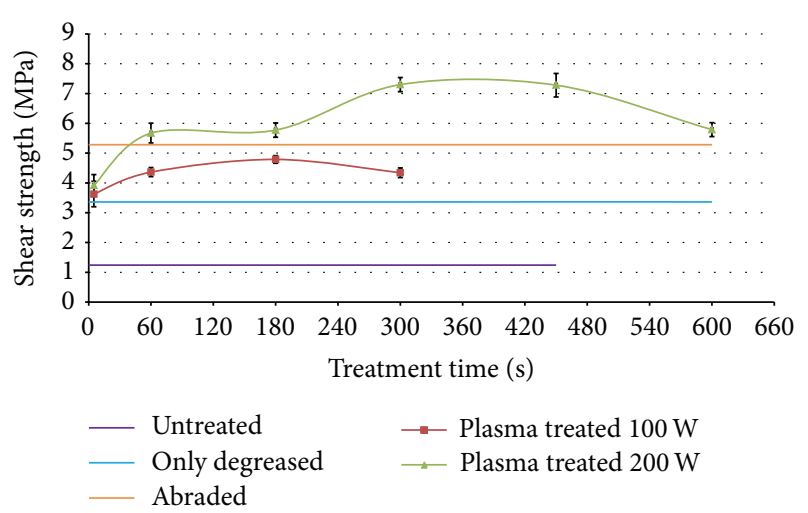

Figure 3: Comparison between shear strength of plasma treated and other samples.

degreasing the surfaces before bonding with acetone, even if this preparation was not satisfactory and it corresponded to adhesive failure of the joints tested.

A typical mechanical pretreatment of abrasion of the surface gave a very good result. Being very careful not to reach the carbon fibre, it is in fact one of the most applied methods to increase the adhesion properties of the surface. This is confirmed by the failure mode, which is partially cohesive. Figure 4 compares the failure surfaces after lap-shear test of samples prepared with only degreasing (Figure 4(a)) and abrasion (Figure 4(b)).

A $100 \mathrm{~W}$ plasma preparation is not enough to overcome the abrasion treatment. Since the tests were performed step by step analysing the data acquired, this power input series
TABLE 4: Mode of failure of the adhesive joints with different surface treatments of the substrates.

\begin{tabular}{|c|c|c|c|}
\hline Surface treatment & & Mode of failure & $\begin{array}{c}\text { Standard } \\
\text { deviation (\%) }\end{array}$ \\
\hline No treatment & & $100 \%$ adhesive & - \\
\hline Solvent treatment & & $100 \%$ adhesive & - \\
\hline Abrasion & & $\begin{array}{c}25 \% \text { cohesive in } \\
\text { adhesive }\end{array}$ & 10 \\
\hline \multicolumn{4}{|l|}{ Plasma treatment } \\
\hline Power input (W) & Time (s) & & \\
\hline 100 & 5 & $100 \%$ adhesive & - \\
\hline 100 & 60 & $100 \%$ adhesive & - \\
\hline 100 & 180 & $100 \%$ adhesive & - \\
\hline 100 & 300 & $100 \%$ adhesive & - \\
\hline 100 & 450 & - & - \\
\hline 100 & 600 & - & - \\
\hline 200 & 5 & $\begin{array}{l}15 \% \text { cohesive in } \\
\text { adhesive }\end{array}$ & 5 \\
\hline 200 & 60 & $\begin{array}{l}48 \% \text { cohesive in } \\
\text { adhesive }\end{array}$ & 8 \\
\hline 200 & 180 & $\begin{array}{l}\text { 53\% cohesive in } \\
\text { adhesive }\end{array}$ & 12 \\
\hline 200 & 300 & $\begin{array}{l}\text { 95\% cohesive in } \\
\text { adhesive }\end{array}$ & 4 \\
\hline 200 & 450 & $\begin{array}{l}98 \% \text { cohesive in } \\
\text { adhesive }\end{array}$ & 2 \\
\hline 200 & 600 & $\begin{array}{c}52 \% \text { cohesive in } \\
\text { adhesive }\end{array}$ & 13 \\
\hline
\end{tabular}

investigation was interrupted at $300 \mathrm{~s}$ to switch to a higher power level. The poor result is also confirmed by the fact that, using this power input, the failure mode is completely adhesive for all the exposure times.

On the contrary, a $60 \mathrm{~s}$ exposure to the plasma discharge with a power input of $200 \mathrm{~W}$ is sufficient to reach and overcome the mechanical properties of the abraded specimens. Using this power input, the best results were obtained for two exposure times: $300 \mathrm{~s}$ and $450 \mathrm{~s}$. Observing Figure 3 it is possible to note that, for this power level, the shear strength increases until a $450 \mathrm{~s}$ treatment, while for longer exposure time the effect is negative and the strength decreases. In fact, if the plasma treatment is too aggressive, the surface will be overetched and its uniformity will decline and might also be damaged by heat generated during the treatment.

The good results of the bonded joints treated with the optimal parameter setup were confirmed by their failure mode.

Figure 5 reports two examples of failure surfaces of joints realized with plasma treated samples, with two different power-time setups. Comparing the images and still more by reading the data in Table 4 , it can be observed that the effect of treatment time on the failure mode repeats exactly that already seen for the shear strength: the percentage of cohesive failure grows to $450 \mathrm{~s}$ and decreases for higher treatment times. 


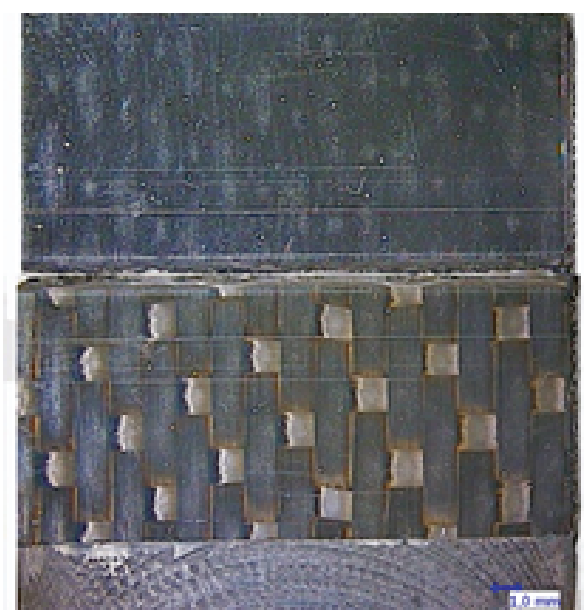

(a)

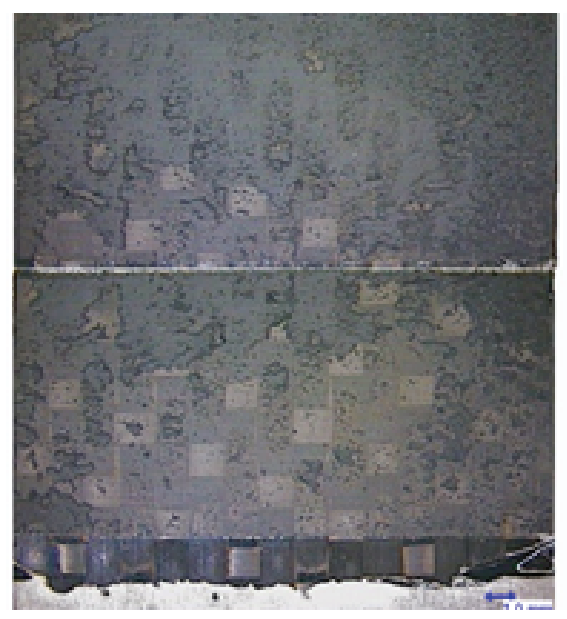

(b)

FIGURE 4: Failure surfaces of joints realized with samples only degreased (a) and abraded (b) after lap-shear test.

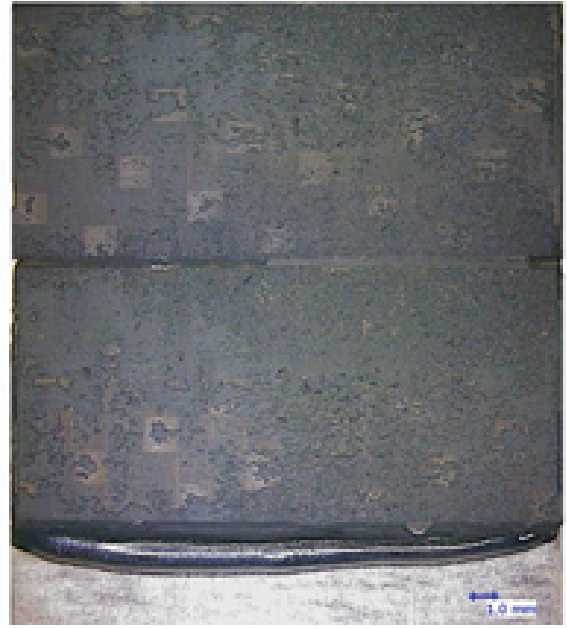

(a)

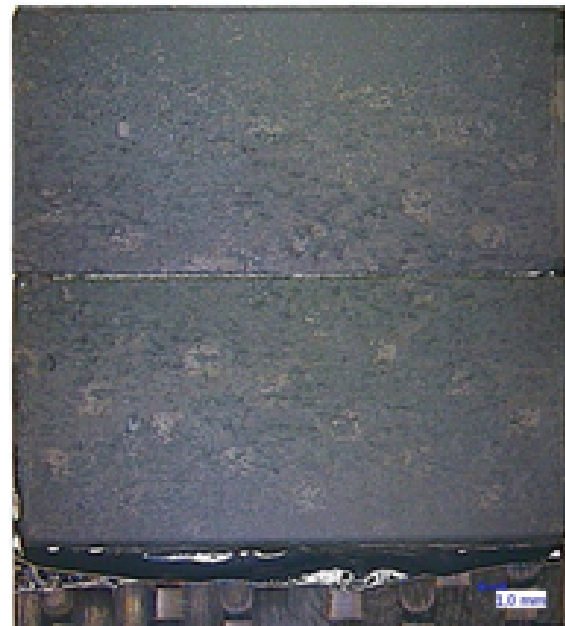

(b)

FIGURE 5: Failure surfaces of joints realized with plasma treated samples with different power-time setup: $200 \mathrm{~W}-180 \mathrm{~s}$ (a) and $200 \mathrm{~W}-450 \mathrm{~s}$ (b) after lap-shear test.

The literature on the relationship between the parameters used in the cold plasma treatment and shear properties of the joints obtained using the treated composite substrates is rather limited. However, the results of this research are comparable with some research conducted by Shanahan and Bourgès-Monnier [19] and Gude et al. [21] for an epoxy composite, by Saleema et al. in two of his works $[32,39]$ for aluminium supports, and by Anagreh et al. [23] and De Iorio et al. [27] for polymeric substrates.

Finally, it was found that there is a correlation between the shear strength properties of the adhesive joints and their failure mode and this is clearly visible comparing the results in Tables 3 and 4. This has already been analysed in several works and in particular by Gude et al. [21] for this substrate. In fact, it is already known that the worst mechanical performance takes place when the joints fail through the adhesive/substrate interface and the application of surface treatments is precisely used to avoid the adhesive failure mode. In the joints realized using $200 \mathrm{~W}$ plasma treated samples, the percentage of cohesive failure mode increases with the treatment time, in the same way as the shear strength. In fact, the best shear properties are obtained when the failure mode is $98 \%$ cohesive.

From the results of this research and from literature, it is clear that plasma power input and treatment time significantly affected the mechanical properties of adhesive bonding joints. Finding the optimal combination of these parameters it is possible to obtain joints characterized by very high strength.

\section{Conclusions}

This study focused on the effect of cold plasma treatment on CFRP substrates. The improvement in adhesion properties 
of plasma treated polymers has been described in terms of wettability, evaluated by contact angle measurement, lapshear strength of the adhesive bonded joints realized using treated surfaces, and failure mode that occurred after these tests. The results were also compared with untreated, only degreased with acetone, and abraded ones.

The results have primarily emphasized how critical the surface preparation is to obtain good joints. The plasma treatment has proven to be quite effective and in particular the following occurs.

(i) Surface wettability improves as the plasma exposure time increases, as shown by the reduction of the contact angle. This is due to the almost total removal of pollutants and to surface activation.

(ii) The plasma treatment effectiveness is also confirmed by a significant improvement of the strength as power input and exposure time increase. It is worthy of notice that it is possible to exceed the shear limit obtained with abraded treated joints even within quite short time periods ( $60 \mathrm{~s}$ ).

(iii) The fraction of cohesion failure increases by using plasma instead of abrasion and it is possible to reach the best result choosing the appropriate parameters.

The activation by plasma represents a fast and ecofriendly technology to more traditional methods, as only degreasing or degreasing followed by mechanical abrasion.

\section{Conflict of Interests}

All the authors declare that there is no conflict of interests regarding the publication of this paper.

\section{Acknowledgments}

The authors wish to thank Gambetti Kenologia S.r.l, for the plasma reactor supply, and 3M Italy for the materials and all their support in carrying out this investigation.

\section{References}

[1] P. Colombi, G. Fava, and C. Poggi, "End debonding of CFRP wraps and strips for the strengthening of concrete structures," Composite Structures, vol. 111, no. 1, pp. 510-521, 2014.

[2] A. M. López-Buendía, M. D. Romero-Sánchez, V. Climent, and C. Guillem, "Surface treated polypropylene (PP) fibres for reinforced concrete," Cement and Concrete Research, vol. 54, pp. 29-35, 2013.

[3] S. K. Ha, S. Na, and H. K. Lee, "Bond characteristics of sprayed FRP composites bonded to concrete substrate considering various concrete surface conditions," Composite Structures, vol. 100, pp. 270-279, 2013.

[4] C. Garnier, M.-L. Pastor, F. Eyma, and B. Lorrain, "The detection of aeronautical defects in situ on composite structures using non destructive testing," Composite Structures, vol. 93, no. 5, pp. 1328-1336, 2011.

[5] Y. He, G. Tian, M. Pan, and D. Chen, "Non-destructive testing of low-energy impact in CFRP laminates and interior defects in honeycomb sandwich using scanning pulsed eddy current," Composites Part B: Engineering, vol. 59, pp. 196-203, 2014.

[6] A. Castellano, P. Foti, A. Fraddosio, S. Marzano, and M. D. Piccioni, "Mechanical characterization of CFRP composites by ultrasonic immersion tests: experimental and numerical approaches," Composites B: Engineering, vol. 66, pp. 299-310, 2014.

[7] A. Al-Shawaf, "Modelling wet lay-up CFRPsteel bond failures at extreme temperatures using stress-based approach," International Journal of Adhesion and Adhesives, vol. 31, no. 6, pp. 416428, 2011.

[8] R. Sturm, Y. Klett, C. Kindervater, and H. Voggenreiter, "Failure of CFRP airframe sandwich panels under crash-relevant loading conditions," Composite Structures, vol. 112, no. 1, pp. 11-21, 2014.

[9] M. S. Found, J. R. Lamb, P. Moore, and M. W. Jones, "Comparison of damage resistance of CFRP lightweight panels," Composites Part A, vol. 36, no. 2, pp. 197-203, 2005.

[10] N. Encinas, B. R. Oakley, M. A. Belcher et al., "Surface modification of aircraft used composites for adhesive bonding," International Journal of Adhesion and Adhesives, vol. 50, pp. 157163,2014

[11] K. Zhang, Z. Yang, and Y. Li, "A method for predicting the curing residual stress for CFRP/Al adhesive single-lap joints," International Journal of Adhesion and Adhesives, vol. 46, pp. 713, 2013.

[12] E. M. Petrie, Handbook of Adhesives and Sealants, McGraw-Hill, New York, NY, USA, 2000.

[13] A. Baldan, "Adhesively-bonded joints and repairs in metallic alloys, polymers and composite materials: adhesives, adhesion theories and surface pretreatment," Journal of Materials Science, vol. 39, no. 1, pp. 1-49, 2004.

[14] R. F. Wegman and J. van Twisk, Surface Preparation Techniques for Adhesive Bonding, Elsevier, London, UK, 2013.

[15] ASTM D2093-03, "Standard Practice for Preparation of Surfaces of Plastics Prior to Adhesive Bonding," 2003.

[16] M. Kanerva and O. Saarela, "The peel ply surface treatment for adhesive bonding of composites: a review," International Journal of Adhesion \& Adhesives, vol. 43, pp. 60-69, 2013.

[17] Q. Bénard, M. Fois, M. Grisel, and P. Laurens, "Surface treatment of carbon/epoxy and glass/epoxy composites with an excimer laser beam," International Journal of Adhesion and Adhesives, vol. 26, no. 7, pp. 543-549, 2006.

[18] M. Rotel, J. Zahavi, S. Tamir, A. Buchman, and H. Dodiuk, "Prebonding technology based on excimer laser surface treatment," Applied Surface Science, vol. 154-155, pp. 610-616, 2000.

[19] M. E. R. Shanahan and C. Bourgès-Monnier, "Effects of plasma treatment on the adhesion of an epoxy composite," International Journal of Adhesion and Adhesives, vol. 16, no. 2, pp. 129-135, 1996.

[20] T. S. Williams, H. Yu, P.-C. Yeh, J.-M. Yang, and R. F. Hicks, "Atmospheric pressure plasma effects on the adhesive bonding properties of stainless steel and epoxy composites," Journal of Composite Materials, vol. 48, no. 2, pp. 219-233, 2014.

[21] M. R. Gude, S. G. Prolongo, and A. Ureña, "Adhesive bonding of carbon fibre/epoxy laminates: correlation between surface and mechanical properties," Surface and Coatings Technology, vol. 207, pp. 602-607, 2012.

[22] M. O. H. Cioffi, H. J. C. Voorwald, L. R. O. Hein, and L. Ambrosio, "Effect of cold plasma treatment on mechanical properties of PET/PMMA composites," Composites Part A: 
Applied Science and Manufacturing, vol. 36, no. 5, pp. 615-623, 2005.

[23] N. Anagreh, L. Dorn, and C. Bilke-Krause, "Low-pressure plasma pretreatment of polyphenylene sulfide (PPS) surfaces for adhesive bonding," International Journal of Adhesion \& Adhesives, vol. 28, no. 1-2, pp. 16-22, 2008.

[24] C. Tendero, C. Tixier, P. Tristant, J. Desmaison, and P. Leprince, "Atmospheric pressure plasmas: a review," Spectrochimica Acta B: Atomic Spectroscopy, vol. 61, no. 1, pp. 2-30, 2006.

[25] W. Petasch, E. Räuchle, M. Walker, and P. Elsner, "Improvement of the adhesion of low-energy polymers by a short-time plasma treatment," Surface and Coatings Technology, vol. 74-75, no. 2, pp. 682-688, 1995.

[26] V. Fombuena, J. Balart, T. Boronat, L. Sánchez-Nácher, and D. Garcia-Sanoguera, "Improving mechanical performance of thermoplastic adhesion joints by atmospheric plasma," Materials and Design, vol. 47, pp. 49-56, 2013.

[27] I. De Iorio, C. Leone, L. Nele, and V. Tagliaferri, "Plasma treatments of polymeric materials and $\mathrm{Al}$ alloy for adhesive bonding," Journal of Materials Processing Technology, vol. 68, no. 2, pp. 179-183, 1997.

[28] H. M. S. Iqbal, S. Bhowmik, and R. Benedictus, "Surface modification of high performance polymers by atmospheric pressure plasma and failure mechanism of adhesive bonded joints," International Journal of Adhesion and Adhesives, vol. 30, no. 6, pp. 418-424, 2010.

[29] C. Mandolfino, E. Lertora, C. Gambaro, and M. Bruno, "Improving adhesion performance of polyethylene surfaces by cold plasma treatment," Meccanica, vol. 49, no. 10, pp. 22992306, 2014.

[30] C. Mühlhan, S. Weidner, J. Friedrich, and H. Nowack, "Improvement of bonding properties of polypropylene by lowpressure plasma treatment," Surface and Coatings Technology, vol. 116-119, pp. 783-787, 1999.

[31] U. Schulz, P. Munzert, and N. Kaiser, "Surface modification of PMMA by DC glow discharge and microwave plasma treatment for the improvement of coating adhesion," Surface and Coatings Technology, vol. 142-144, pp. 507-511, 2001.

[32] N. Saleema and D. Gallant, "Atmospheric pressure plasma oxidation of AA6061-T6 aluminum alloy surface for strong and durable adhesive bonding applications," Applied Surface Science, vol. 282, pp. 98-104, 2013.

[33] http://solutions.3mitalia.it/wps/portal/3M/it_IT/Industrial-Adhesives-and-Tapes/IATD/.

[34] L. Carrino, G. Moroni, and W. Polini, "Cold plasma treatment of polypropylene surface: a study on wettability and adhesion," Journal of Materials Processing Technology, vol. 121, no. 2-3, pp. 373-382, 2002.

[35] J. K. Park, W. T. Ju, K. H. Paek et al., "Pre-treatments of polymers by atmospheric pressure ejected plasma for adhesion improvement," Surface and Coatings Technology, vol. 174-175, pp. 547-552, 2003.

[36] ASTM, "Standard test method for lap shear adhesion for Fiber Reinforced Plastic (FRP) bonding," ASTM D5868-01, ASTM International, 2014.

[37] C. J. Lee, S. K. Lee, D. C. Ko, D. J. Kim, and B. M. Kim, "Evaluation of surface and bonding properties of cold rolled steel sheet pretreated by $\mathrm{Ar} / \mathrm{O}_{2}$ atmospheric pressure plasma at room temperature," Journal of Materials Processing Technology, vol. 209, no. 10, pp. 4769-4775, 2009.
[38] N. Encinas, J. Abenojar, and M. A. Martínez, "Development of improved polypropylene adhesive bonding by abrasion and atmospheric plasma surface modifications," International Journal of Adhesion and Adhesives, vol. 33, pp. 1-6, 2012.

[39] N. Saleema, D. K. Sarkar, R. W. Paynter, D. Gallant, and M. Eskandarian, "A simple surface treatment and characterization of AA 6061 aluminum alloy surface for adhesive bonding applications," Applied Surface Science, vol. 261, pp. 742-748, 2012. 

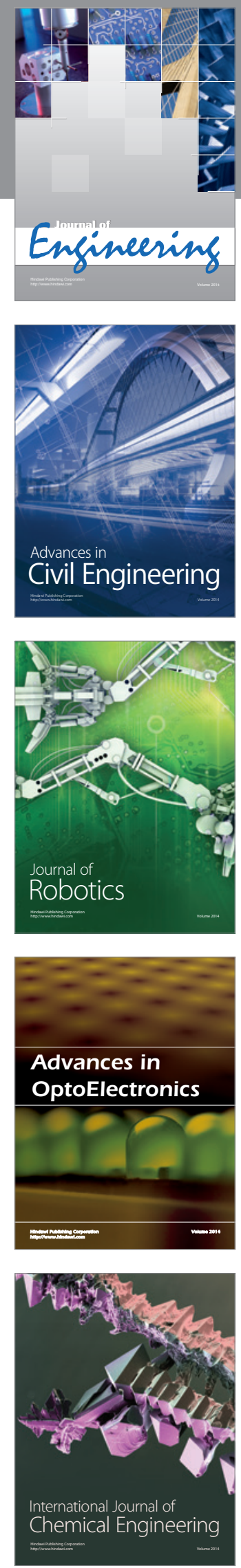

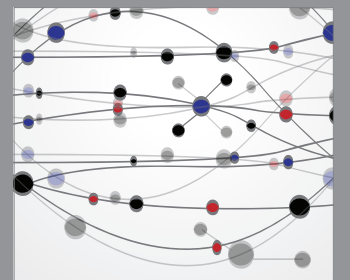

The Scientific World Journal
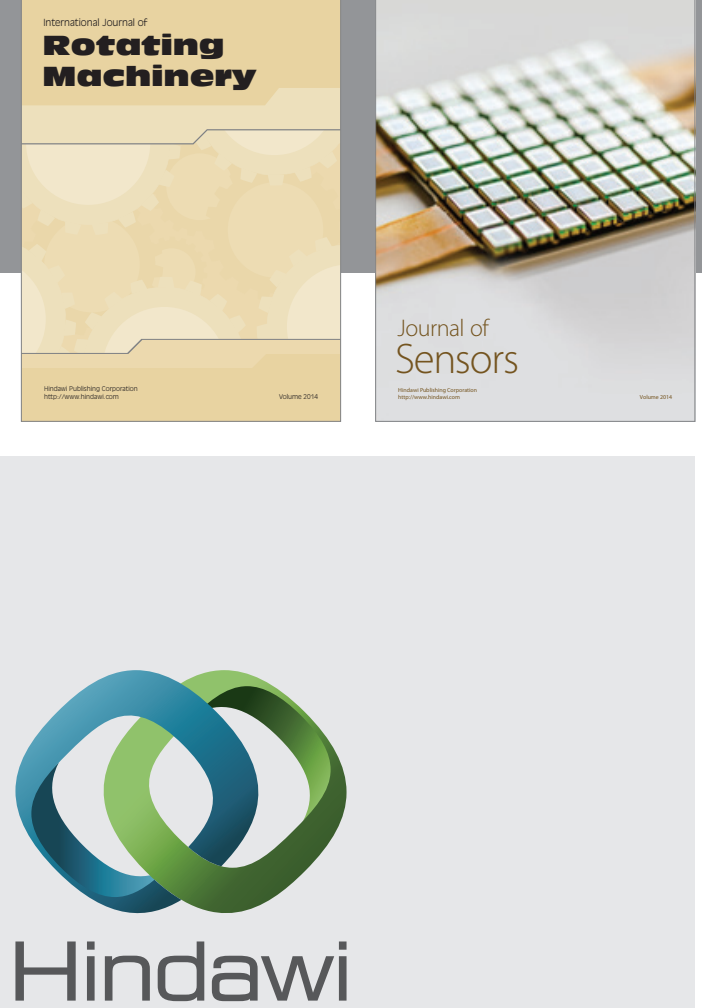

Submit your manuscripts at http://www.hindawi.com
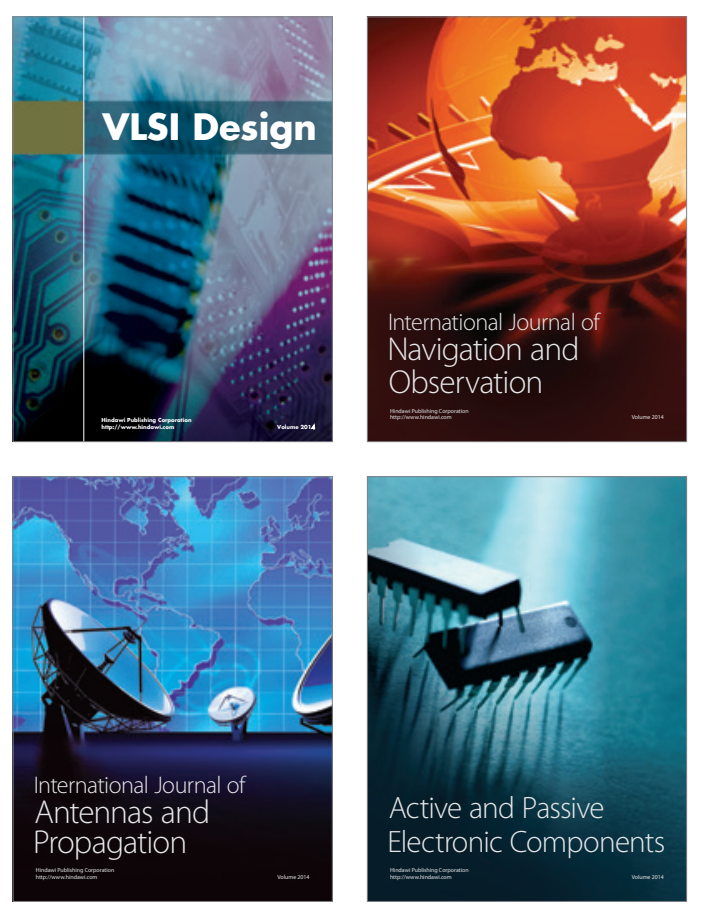
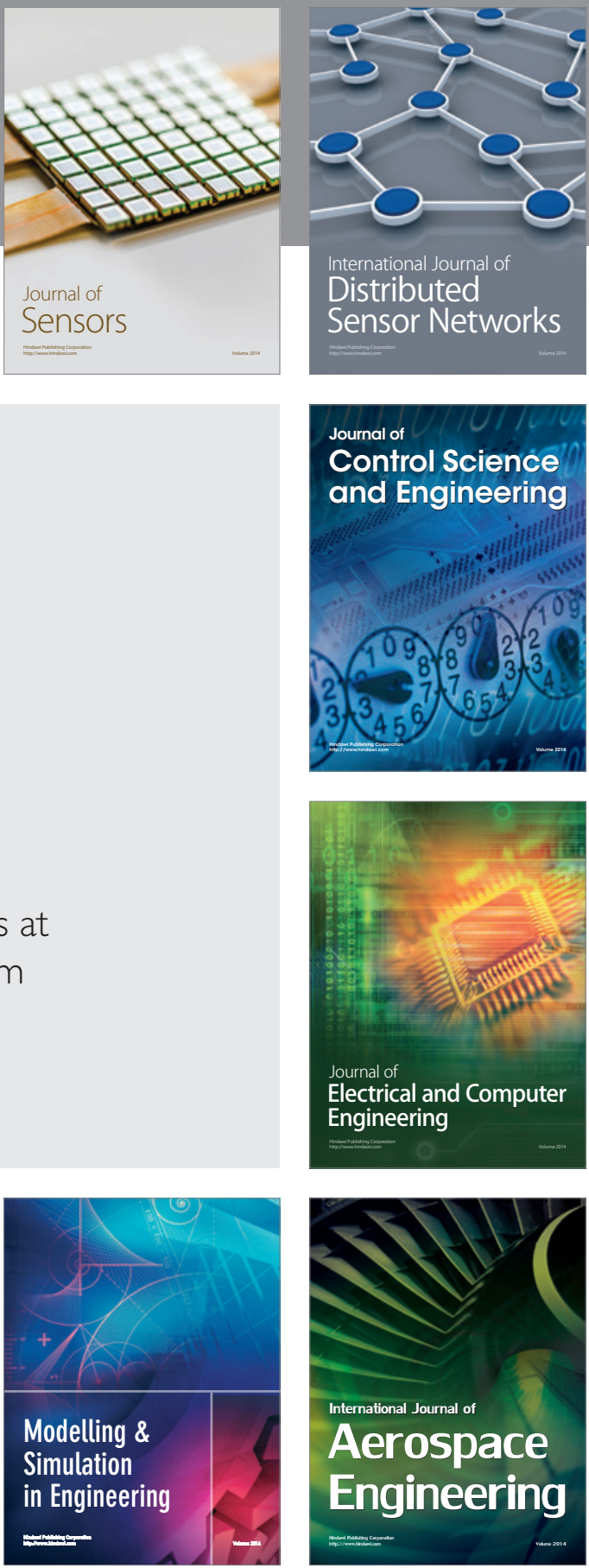

Journal of

Control Science

and Engineering
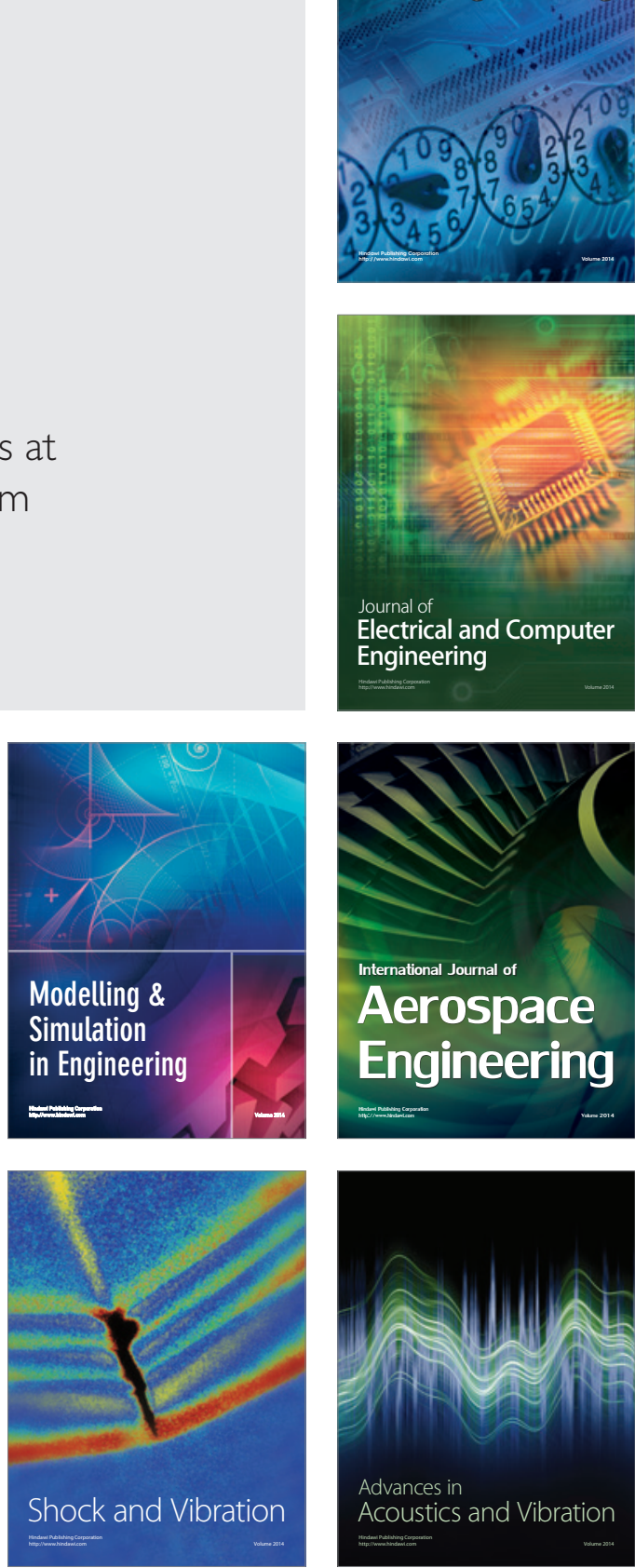